\title{
Antioxidant Activity and Total Polyphenol Content of Royal Jelly from Bulgaria
}

\author{
Ralitsa Balkanska $^{1^{*}}$, Liviu-Alexandru Marghitas ${ }^{2}$ and Crenguta Ioana Pavel ${ }^{2}$ \\ ${ }^{1}$ Department of Special Branches - Bees, Institute of Animal Science, Kostinbrod, Spirka \\ Pochivka 1, 2232, Bulgaria \\ ${ }^{2}$ Department of Beekeeping and Sericulture, University of Agricultural Sciences and Veterinary \\ Medicine Cluj-Napoca, Calea Manastur 3-5, 400372, Romania \\ *Corresponding author
}

\begin{tabular}{|c|c|}
\hline & A B S T R A C T \\
\hline $\begin{array}{l}\text { Royal jelly, } \\
\text { Antioxidant activity, } \\
\text { Total polyphenols, } \\
\text { Bulgarian RJ, DPPH, } \\
\text { FRAP. }\end{array}$ & \multirow{3}{*}{$\begin{array}{l}\text { This study aimed to screen the antioxidant activity of royal jelly (RJ) } \\
\text { collected from } 2 \text { regions of Bulgaria (Lovech and Veliko Tarnovo) and RJ } \\
\text { samples from the market using the 1,1-diphenyl-2-picrylhydrazyl (DPPH) } \\
\text { method for antiradical activity and the ferric reducing antioxidant power } \\
\text { (FRAP) assay. Total phenolic content was determined according to Folin- } \\
\text { Ciocalteu procedure. All RJ samples were able to scavenge free radicals in } \\
\text { wide ranges ( } 10.17 \text { - } 39.39 \% \text { inhibition). The FRAP and total polyphenols } \\
\text { also showed high variability and a correlation between them was found. For } \\
\text { the all samples the following ranges were obtained: FRAP } 0.44-8.49 \mathrm{mM} \\
\mathrm{Fe}^{2+} / \mathrm{g} \text {, total polyphenols } 11.66-36.73 \text { (mg GAE/g). }\end{array}$} \\
\hline Article Info & \\
\hline $\begin{array}{l}\text { Accepted: } \\
\text { 07 September } 2017 \\
\text { Available Online: } \\
10 \text { October } 2017\end{array}$ & \\
\hline
\end{tabular}

\section{Introduction}

In the recent years, consumer and market demand are showing increased interest in natural products with health-promoting effects. Among them, the bee products as popular and traditional health foods have generated considerable interest. Royal jelly (RJ) is one of the most attractive bee products. RJ is the principal food of the honeybee queen and it is produced by hypopharyngeal and mandibular glands of worker honeybees (Isidorov et al., 2009). It is composed mainly of proteins, sugars, lipids, free amino acids, vitamins and mineral elements. RJ has been demonstrated to possess a number of pharmacological activities. For this reason, it is widely used in medical products, health foods and cosmetics in many countries (Guo et al., 2009).

It has been reported that $\mathrm{RJ}$ has antitumor (Nakaya et al., 2007; Izuta et al., 2009), antibacterial (Fujiwara et al., 1990), cardioprotective (Krylov et al., 2006), hypotensive (Tokunaga et al., 2004), antiinflammatory (Kohno et al., 2004), antifatigue (Kamakura et al., 2001), hypoglycaemic activity (Fujii et al., 1990), estrogenic effect (Mishima et al., 2005) and 
effects on fertility (Husein and Kridli, 2002). Furthermore, RJ has anti-inflammatory activity and wound-healing properties (Fujii et al., 1990), insulin-like (Okuda et al., 1998; Salazar-Olivo and Paz-Gonzales, 2005), liverprotecting activity (Karadeniz et al., 2011; Kanbur et al., 2009) and promotes collagen production (Koya-Miyata et al., 2004).

The DPPH and FRAP assays are widely used to evaluate antioxidant activity in different natural products. The DPPH radical scavenging test is one of the simplest methods available to investigate the overall hydrogen/electron-donating activity of single antioxidants and health-promoting dietary antioxidant supplements (Kedare and Singh, 2011). The FRAP assay uses antioxidants as reductants in a redox-linked colorimetric method, employing an easily reduced oxidant system present in stoichiometric excess.

There are a few reports about its antioxidative role connected to antiaging effects (Iannuzzi, 1990; Inoue et al., 2003) and reduction of intracellular oxidation (Jamnik et al., 2007). Royal jelly also prevents radiation-induced brain damage (Cihan et al., 2011). Biological activities of royal jelly are mainly attributed to bioactive fatty acids, proteins and phenolic compounds (Jamnik et al., 2012; Ramadan and Al-Ghamdi, 2012).

Antioxidants are compounds that can delay or inhibit the oxidation of lipids or other molecules by inhibiting the initiation or propagation of oxidative chain reactions (Velioglu et al., 1998). The antioxidant activity of phenolic compounds is mainly due to their redox properties, which can play an important role in absorbing and neutralizing free radicals (Javanmardi et al., 2003).

Several studies have been previously conducted on the antioxidant activity of RJ (Inoue et al., 2003; Nagai et al., 2006; Barnutiu, 2013). However, there is no study to present the antioxidant activity and total polyphenolic content of Bulgarian RJ.

In this respect, the purpose of the present study is to evaluate the antioxidant activity and to determine the total polyphenol content in Bulgarian RJ samples.

\section{Materials and Methods}

A total of 20 samples from Bulgaria were obtained from experimental apiaries (from 2 regions - Lovech (8 RJ samples), Veliko Tarnovo (7 RJ samples) and directly from market (5 RJ samples).

Antioxidant activity of RJ was estimated by determination of DPPH (2, 2-diphenyl-1picrylhydrazyl), according to the procedure of Brand-Williams et al., (1995) and modified after Liu et al., (2008). FRAP assay (Ferric Reducing Antioxidant Power) (Benzie and Strain, 1996) was performed as described in Mohammadzadeh et al., (2007) with modification of sample preparation. For both methods, $1 \mathrm{mM}$ ascorbic acid was used as positive control (DPPH - 98.21\% inhibition, FRAP - $\left.14.77 \mathrm{mM} \mathrm{Fe}^{2+} / \mathrm{g}\right)$.

Total polyphenol content was determined by Folin - Ciocalteu colorimetric method (Slinkard and Singleton, 1977) using gallic acid as a calibration standard as described in Liu et al., (2008) with measuring the absorbance at $760 \mathrm{~nm}$.

All measurements were performed from dilutions of $10 \%$ RJ in bidistilled water. All analysis was done in Laboratory of Quality Control for Bee Products, Cluj-Napoca.

The analyses were carried out in triplicate and the data were expressed as means \pm standard deviations (SD). Statistical analyses of data were performed using IBM SPSS Statistics version 21 for Windows. Correlation analyses between the antioxidant parameters and total 
polyphenols were done. The Student's t-test was used to determine the significance of the differences. Level of statistical significance was defined as $\mathrm{p}<0.05$.

\section{Results and Discussion}

The results for DPPH and FRAP assays are presented in Table 1 which summarize the average values \pm standard deviations and ranges for all RJ samples. All tested RJ samples exhibit antioxidant activity.

A few articles deal with the antioxidant activity of RJ. Using the same equipment and technique for both DPPH and FRAP Pavel et al., (2014) obtained higher DPPH values than in this study (an average of $37.23 \%$ inhibition in Romanian RJ). On the contrary Bulgarian samples have higher average values for FRAP $\left(3.50 \pm 2.41 \mathrm{mM} \mathrm{Fe}^{2+} / \mathrm{g}\right)$ than Romanian samples $(2.20 \mathrm{mM} \mathrm{Fe} / \mathrm{g})$. This parameter varies within a larger range (Table 1) than the results obtained by the same authors, (1.50 $\left.3.81 \mathrm{mM} \mathrm{Fe}{ }^{2+} / \mathrm{g}\right)$. Ceksteryte et al., (2016) also studied the antioxidant activity of RJ samples but they used different scale for DPPH.

The total polyphenol contents of analysed RJ samples are shown in Table 1. The values varied in following range: $11.66-36.73 \mathrm{mg}$ GAE/g RJ with an average of $19.54 \mathrm{mg}$ $\mathrm{GAE} / \mathrm{g}$. Our results are similar to those presented by Pavel et al., (2014) (14.56 $39.90 \mathrm{mg}$ GAE/g RJ). Lui et al., (2008) studied the antioxidant activity of RJ collected 24, 48 and $72 \mathrm{~h}$ after the larval transfer. RJ collected $72 \mathrm{~h}$ after the larval transfer had $168.0 \pm 5.9 \mu \mathrm{g} / \mathrm{g}$ total phenolic content. This value is much lower than the average value obtained in the present study (Table 1). Ceksteryte et al., (2016) also received lower average value for this parameter $(10.7 \pm 0.03 \mathrm{mg} \mathrm{GAE} / \mathrm{g})$.

The phenolic compounds or polyphenols are one of the most important groups of compounds occurring in plants where they are widely distributed. The polyphenols are also products of the secondary metabolism of plants. These compounds are reported to exhibit anticarcinogenic, anti-inflammatory, anti-atherogenic, antithrombotic, immune modulating and analgesic activities, among others and exert these functions as antioxidants (Gomez-Caravaca et al., 2006). The phenolic compounds present in royal jelly are known to possess antioxidant properties and these properties may play a key role in the pharmacological activities of RJ.

The spectrophotometric procedure with Folin-Ciocalteu reagent is widely used to determine total phenolic content in different bee products (Lachman et al., 2010; Serra Bonvehi and Gutierrez, 2011). A positive correlation between the total antioxidant activity determined by the FRAP method and total phenolic content (Figure 1) for all RJ samples was observed. The moderate correlation coefficient $(r=0.461, \quad p<0.05)$ indicates that the phenolics are one of the components responsible for the antioxidant behaviour of RJ. This result suggests that only $21 \%$ of the antioxidant capacity of the RJ samples accessions results from the contribution of the total polyphenols.

Table.1 Antioxidant activity expressed by DPPH and FRAP assays and total polyphenols in Bulgarian RJ samples, $n=20$

\begin{tabular}{llll}
\cline { 2 - 4 } & DPPH $(\%$ inhibition $)$ & FRAP $\left(\mathbf{m M ~ F e}^{2+} / \mathbf{g}\right)$ & Total polyphenols (mg GAE/g) $^{\text {Fols }}$ \\
\hline Average \pm SD & $24.23 \pm 8.19$ & $3.50 \pm 2.41$ & $19.54 \pm 6.12$ \\
Range & $10.17-39.39$ & $0.44-8.49$ & $11.66-36.73$ \\
\hline
\end{tabular}


Fig.1 Correlation between FRAP assay and total polyphenols of Bulgarian RJ samples $\mathrm{R}^{2}=0.213$, $(\mathrm{p}<0.05), \mathrm{y}=\mathrm{e}^{2.2-0.65 . x}$

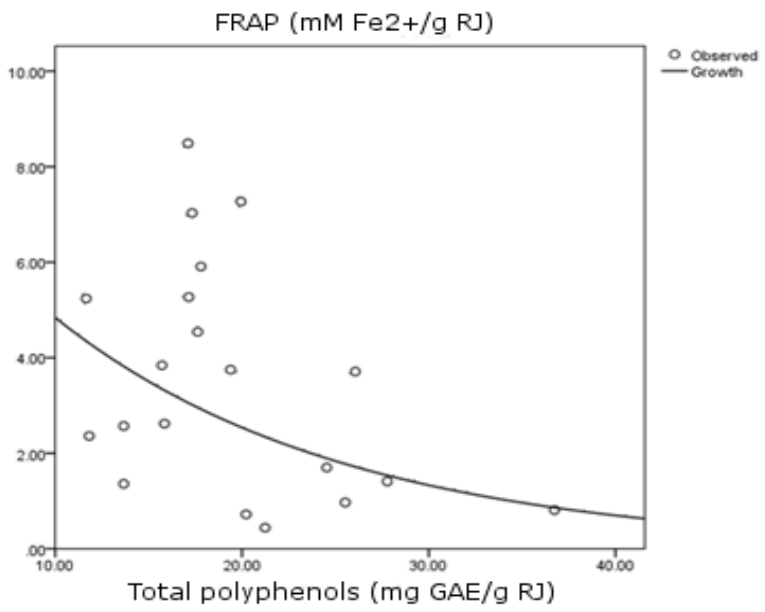

Fig.2 Average values and standard deviation of DPPH, FRAP and total polyphenols between RJ samples from different regions of Bulgaria, (A-C), $n=15$
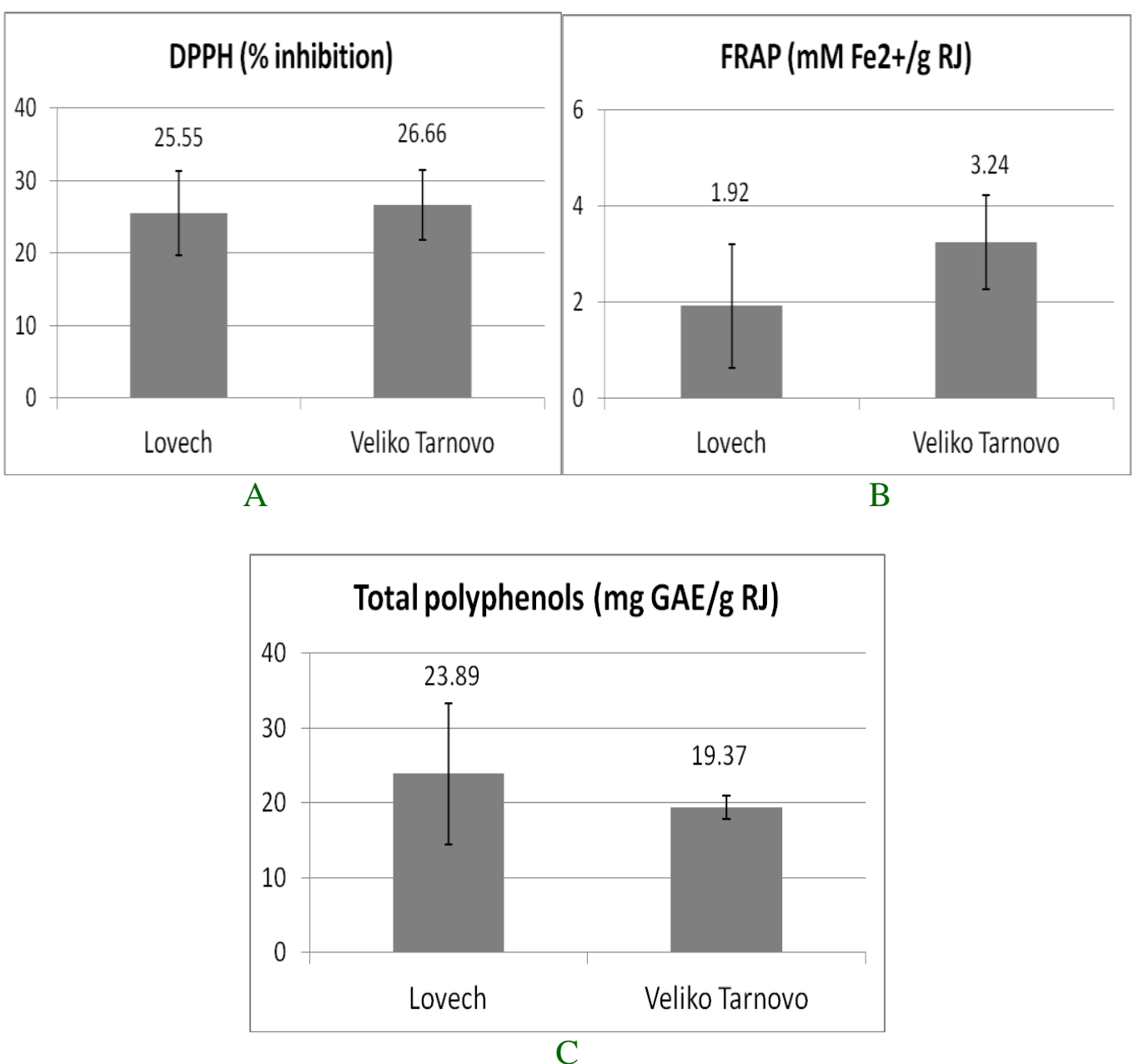
It can be concluded that antioxidant activity of RJ is not due to total polyphenols exclusively. Activity may also result from the presence of other antioxidant secondary metabolites from pollen grains in RJ. The antioxidant activity of phenolic compounds is mainly due to their redox properties, which allow them to act as reducing agents, hydrogen donors and singlet oxygen quenchers. The unique feature of RJ is 10 hydroxy-2-decenoic known to possess various pharmacological effects, including antioxidative action (Nagai et al., 2001; Nagai et al., 2006; Isidorov et al., 2011). It has also been suggested that organic acids present in RJ contribute to antioxidant activity through metal chelation and increase the effect of total polyphenols. These findings show that other components which are not analysed in our study should also play an important role for antioxidant activity of RJ. As previously mentioned the antioxidant activity is basically due to the presence of different compounds, although the exact action mechanism is unknown.

As a first step in characterization of Bulgarian RJ samples for antioxidant activity and total polyphenols the results are presented more comprehensively for 2 Bulgarian regions (Lovech and Veliko Tarnovo). The values obtained for DPPH, FRAP and total polyphenols do not vary greatly among these 2 regions, as is showed in Figure 2.

It should be mentioned that these 2 regions are not identical in floral sources. The DPPH values between the two regions are almost identical. The RJ samples from Veliko Tarnovo have higher values for FRAP analysis. The total polyphenols in the samples increased in the following order: RJ from Veliko Tarnovo < RJ from Lovech region. The differences for all analysed parameters are not significant. The composition of RJ and its antioxidant capacity can be influenced by a large number of factors, such as the flower source of the nectar, environmental factors and processing methods. Therefore, it cannot be fully evaluated by one single method. Moreover, it is necessary to perform more than one type of antioxidant capacity method for taking into account the various mechanisms of antioxidant action.

To the best of our knowledge, this is the first report of the antioxidant properties of Bulgarian RJ samples. For the all samples the following ranges were obtained: DPPH 10.17 $-39.39 \%$ inhibition, FRAP $0.44-8.49 \mathrm{mM}$ $\mathrm{Fe}^{2+} / \mathrm{g}$, total polyphenols $11.66-36.73$ (mg $\mathrm{GAE} / \mathrm{g})$. The concentration of individual phenolic compounds and antioxidant properties are rather complex and further investigations are needed to determine possible correlations between DPPH, FRAP, total polyphenols and other quality parameters.

\section{References}

Barnutiu, L. I., 2013. Biological properties evaluation of the quality markers from royal jelly and apilarnil. PhD Thesis.

Benzie, I. F., and Strain J. J. 1996. The ferric reducing ability of plasma (FRAP) as a measure of "antioxidant power": the FRAP assay. Analytical Biochemistry 239: $70-76$.

Brand-Williams, W., M. E. Cuvelier and Berset, C. 1995. Use of a free radical method to evaluate antioxidant activity. LWT - Food Science and Technology 28: $25-30$

Ceksteryte, V., B. Kurtinaitienè, P. R. Venskutonis, A. Pukalskas, R. Kazernaviciute and Balžekas J. 2016. Evaluation of antioxidant activity and flavonoid composition in differently preserved bee products. Czech J. Food Sci., 34(2): 133 - 142.

Cihan, Y., V. Arsav and Göcen E. 2011. 
Royal jelly in the prevention of radiation-induced brain damages. Journal of Neurological Sciences 28: $475-486$.

Fujii, A., S. Kobayashi, N. Kuboyama, Y. Furukawa, Y. Kaneko, S. Ishihama, H. Yamamoto and Tamura T. 1990. Augmentation of wound healing by royal jelly in streptozotocin-diabetic rats. The Japanese Journal of Pharmacology 53: 331 - 337.

Fujiwara, S., J. Imai, M. Fujiwara, T. Yaeshima, T. Kawashima and Kobayashi K. A. 1990. A potent antibacterial protein in royal jelly. Purification and determination of the primary structure of royalisin. Journal of Biological Chemistry 265: 11333 11337.

Gomez-Caravaca, A.M., M. Gomez-Romero, D. Arraez-Roman, A. Segura-Carretero, and Fernandez-Gutierrez A. 2006. Advances in the analysis of phenolic compounds in products derived from bees. Journal of Pharmaceutical and Biomedical Analysis 41: 1220 - 1234.

Guo, H., Y. Kouzuma and Yonekura M. 2009. Structures and properties of antioxidative peptides derived from royal jelly protein. Food Chemistry 113: $238-245$.

Husein, M. Q., and Kridli R.T. 2002. Reproductive responses following royal jelly treatment administered orally or intramuscularly into progesteronetreated Awassi ewes. Animal Reproduction Science 74: 45 - 53.

Iannuzzi, J., 1990. Royal jelly: mystery food. American Bee Journal 130: 587 - 589.

Inoue, S.I., S. Koya-Miyata, S. Ushio, K. Iwak, M. Ikeda and Kurimoto M. 2003. Royal jelly prolongs the life span of $\mathrm{C} 3 \mathrm{H} / \mathrm{H} 3 \mathrm{~J}$ mice: correlation with reduced DNA damage. Experimental Gerontology 38: 965 - 969.

Isidorov V.A., Czyzewska U., Isidorova A.G., and Bakier S. 2009. Gas chromatographic and mass spectrometric characterization of the organic acids extracted from some preparations containing lyophilized royal jelly. Journal of Chromatography B 877:3776-3780.

Isidorov, V.A., U. Czyzewska, E. Jankowska and Bakier S. 2011. Determination of royal jelly acids in honey. Food Chemistry 124: 387 - 391.

Izuta, H., Y. Chikaraishi, M. Shimazawa, S. Mishima and Hara H. 2009. 10Hydroxy-2-decenoic acid, a major fatty acid from royal jelly, inhibits VEGFinduced angiogenesis in human umbilical vein endothelial cells. Evidence-Based Complementary and Alternative Medicine 6: 489 - 494.

Jamnik, P., D. Goranovic and Raspor P. 2007. Antioxidative action of royal jelly in the yeast cell. Experimental Gerontology 42: $594-600$

Jamnik, P., P. Raspor and Javornik, B. 2012. A Proteomic Approach for Investigation of Bee Products: Royal Jelly, Propolis and Honey. Food Technology and Biotechnology 50: 270 - 274.

Javanmardi, J., C. Stushnoff, E. Locke and Vivanco J. M. 2003. Antioxidant activity and total phenolic content of Iranian Ocimum accessions. Food Chemistry 83: $547-550$.

Kamakura, M., N. Mitani, T. Fukuda and Fukushima M. 2001. Antifatigue effect of fresh royal jelly in mice. Journal of Nutritional Science and Vitaminology 47: $394-401$

Kanbur, M., G. Eraslan, L. Beyaz, S. Silici, B. C. Liman, S. Altinordulu and Atasever A. 2009. The effects of royal jelly on liver damage induced by paracetamol in mice. Experimental and Toxicologic Pathology 61: 123 - 32.

Karadeniz, A., N. Simsek, E. Karakus, S. Yildirim, A. Kara, I. Can, F. Kisa, H. 
Emre and Turkeli M. 2011. Royal jelly modulates oxidative stress and apoptosis in liver and kidneys of rats treated with cisplatin. Oxidative Medicine and Cellular Longevity 1 10.

Kedare, S. B., and Singh R. P. 2011. Genesis and development of DPPH method of antioxidant assay. J Food Sci Techol, 48 (4): $412-422$.

Kohno, K., I. Okamoto, O. Sano, N. Arai, K. Iwaki, M. Ikeda and Kurimoto M. 2004. Royal jelly inhibits the production of proinflammatory cytokines by activated macrophages. Bioscience Biotechnology and Biochemistry 68: $138-45$.

Koya-Miyata, S., I. Okamoto, S. Ushio, K. Iwaki, M. Ikeda and Kurimoto M. 2004. Identification of a collagen productionpromoting factor from an extract of royal jelly and its possible mechanism. Bioscience Biotechnology and Biochemistry 68: $767-773$.

Krylov, V. N., S.S. Sokolsky and Krylova E.V. 2006. Experimental study of bee royal jelly cardioprotective characteristics. Mellifera 6: 28 - 32 .

Lachman, J., M. Orsak, A. Hejtmankova and Kovarova E. 2010. Evaluation of antioxidant activity and total phenolics of selected Czech honeys. LWT - Food Science and Technology 43: $52-58$.

Liu, J. R., Y. C. Yang, L. S. Shi and Peng C.C. 2008. Antioxidant properties of royal jelly associated with larval age and time of harvest. Journal of Agricultural and Food Chemistry 56: 11447 - 11452.

Mishima, S., K. Suzuki, Y. Isohama, N. Kuratsu, Y. Araki, M. Inoue and Miyata T. 2005. Royal jelly has estrogenic effects in vitro and in vivo. Journal of Ethnopharmacology 101: 215 - 220.

Mohammadzadeh, S., M. Sharriatpanahi, M. Hamedi, Y. Amanzadeh, S. E. S.
Ebrahimi, Ostad S. E. 2007. Antioxidant power of Iranian propolis extract. Food Chemistry 103(3): 729 733.

Nagai, T., M. Sakai, R. Inoue, H. Inoue and Suzuki N. 2001. Antioxidative activities of some commercially honeys, royal jelly, and propolis. Food Chemistry 75: $237-240$

Nagai, T., R. Inoue, N. Suzuki and Nagashima T. 2006. Antioxidant properties of enzymatic hydrolysates from royal jelly. Journal of Medicinal Food 9:363 - 367.

Nakaya, M., H. Onda, K. Sasaki, A. Yukiyoshi, H. Tachibana and Yamada K. 2007. Effect of royal jelly on bisphenol A-induced proliferation of human breast cancer cells. Bioscience Biotechnology and Biochemistry 71: $253-255$.

Okuda, H., K. Kameda, C. Morimoto, Y. Matsuura, M. Chikaki and Jiang M. 1998. Studies on insulin-like substances and inhibitory substances toward angiotensin-converting enzyme in royal jelly. Honeybee Science 19: 9 - 14.

Pavel, C., L. Al. Marghitas, D. Dezmirean, L. Tomos, V. Bonta, A. Sapcaliu and Buttstedt A. 2013. Comparison between local and commercial royal jelly - use of antioxidant activity and 10-hydroxydecenoic acid as quality parameter. Journal of Apicultural Research 53(1): $116-123$

Ramadan, M. F., and Al-Ghamdi, A. 2012. Bioactive compounds and healthpromoting properties of royal jelly: A review. Journal of Functional Foods 4: $39-52$.

Salazar-Olivo, L. A., and Paz-Gonzales, V. 2005. Screening of biological activities present in honeybee (Apis mellifera) royal jelly. Toxicology in Vitro 19: 645 $-651$.

Serra Bonvehi, J., and Gutierrez, A. L. 2011. 
Antioxidant activity and total phenolics of propolis from the Basque Country (Northeastern Spain). Journal of the American Oil Chemists' Society 1387 -1395 .

Slinkard, K., and Singleton, V.L. 1977. Total phenol analysis - automation and comparison with manual methods. American Journal of Enology and Viticulture 28: 49 - 55.

Tokunaga, K. H., C. Yoshida, K. M. Suzuki, H. Maruyama, Y. Futamura, Y. Araki, and Mishima S. 2004. Antihypertensive effect of peptides from royal jelly in spontaneously hypertensive rats. Biological and Pharmaceutical Bulletin 27: $189-192$.

Velioglu, Y. S., G. Mazza, L. Gao and Oomah B. D. 1998. Antioxidant activity and total phenolics in selected fruits, vegetables, and grain products. Journal of Agricultural Food and Chemistry 46: $4113-4117$.

\section{How to cite this article:}

Ralitsa Balkanska, Liviu-Alexandru Marghitas and Crenguta Ioana Pavel. 2017. Antioxidant Activity and Total Polyphenol Content of Royal Jelly from Bulgaria. Int.J.Curr.Microbiol.App.Sci. 6(10): 578-585. doi: https://doi.org/10.20546/ijcmas.2017.610.071 